\title{
Influence of Globalization on Environment
}

\author{
Aditya Narayan Tripathi \\ Education Department at Sant Tulsi Das PG College Kadipur Sultanpur, India
}

Received: 阱 January 22, 2018; Published: 眥 February 05, 2018

*Corresponding author: Aditya Narayan Triapthi, Sant Tulsi Das PG College Kadipur Sultanpur, UP, India

Keywords: Globalization; Feasible; Degradation; Pollution; Stress

\section{Background}

Globalization is a process of interaction and integration among the people, Companies and governments of different nations, a process driven by international trade and investment and Aided by information technology. Globalization has also contributed more in environmental degradation as well. It has led to increase in the consumption of products, affected the ecological cycle, increased consumption leads to an increase in the production of goods, which also creates or puts more stress on the environment. Globalization also causes rise in pollution level in the environment. It has also led to an increase in transportation of raw materials and food from one place to another. Transportation has also put a strain on the non renewable sources of energy such as gasoline. Due to globalization depletion of ozone layer, increasement of green house gases enhancement of deforestation, killing of many underwater organism due to overproduction of industrial wastes and ultimately deposition of harmful chemicals in oceans take place.

Some learned person's definitions are presented here with reference to environment as- Girberts "Environment is anything immediately surrounding an object and exerting direct influence on it." Douglas and Holland "the term environment is used to describe in the aggregate all the external factors, influence and conditions which and effect the life, nature, behavior growth development and maturation of living organism." Ross "Environment is any external force which influence us" Woodworth "Environment cover all the outside factors that have acted on the individual since he began his life". Herskovits "Environment is the sum total of all those external conditions and influences which affect the lives and development of living or organic thing."

a) Aim: This study will give some measures to bring harmony between development and environment Sustainability in this globalization world.

b) Result: We thoroughly studied and analyzed the process of globalization and their challenging impacts on our healthy ecosystem and environment. We have to develop some effective mechanism and also support to building a better structure that can check the extent to which it can impact the environment and certainly it would economically feasible and ecofriendly too.

\section{Conclusion}

Due to globalization pollution level will become reduce.
CC (i) This work is licensed under Creative To Submit Your Article Click Here: Submit Article DOI: 10.32474/MAOPS.2018.01.000104

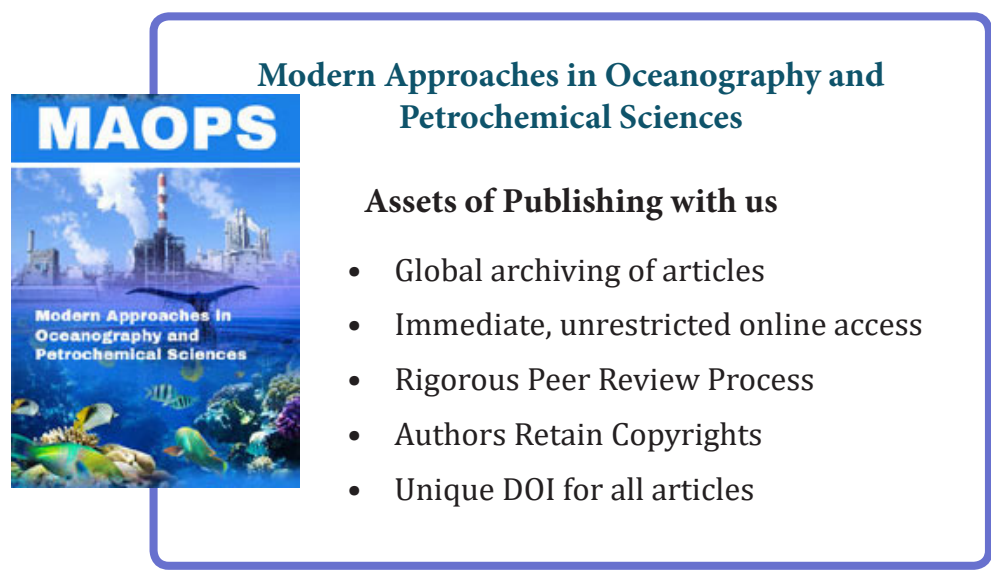

